\title{
Iron Catalyzed C-C Single Bond Cleavage of Alcohols
}

\author{
Wei Liu, $\uparrow$ Qiang Wu, $\uparrow$ Miao Wang, Yahao Huang, Peng $\mathrm{Hu}^{*}$ \\ Lehn Institute of Functional Materials, School of Chemistry, Sun Yat-Sen University, Guangzhou 510006, China
}

\section{Supporting Information Placeholder}

\begin{abstract}
An iron-catalyzed deconstruction/hydrogenation reaction of alcohols through $\mathrm{C}-\mathrm{C}$ bond cleavage is developed under the irradiation of visible light, to produce ketones or aldehydes as the products. Linear alcohols and cycloalkanols with different ring sizes are suitable substrates, containing tertiary, secondary, and primary alcohols bearing a wide range of substitutes. Complex natural alcohols can also perform the transformation selectively. The mechanism investigation reveals an unpresented reaction procedure that involves chlorine radical as a key intermediate, which is generated from $\left[\mathrm{FeCl}_{4}\right]^{-}$through ligand to metal charge transfer (LMCT). The study illustrates new possibilities for iron photocatalysis, especially for various deconstruction/functionalization reactions.
\end{abstract}

Organic synthesis commonly focuses on C-C or C-heteroatom bond formation, to develop methodologies for the construction of new structures and complex compounds. ${ }^{1}$ During the last century, the corresponding methods have been fruitfully created and widely used in both laboratory and industry. ${ }^{2}$ Though powerful, the "step by step" synthesis procedures generally start from simple chemicals and sometimes suffer from low efficiency and show limitations for unique molecular structures. Differently, deconstruction through $\mathrm{C}-\mathrm{C}$ bond scission can provide structurally novel compounds from known chemicals, illustrating another valuable logic for synthesis and showing diverse synthetic possibilities and opportunities. ${ }^{3}$ One attracting consideration of this area is "scaffold hopping", resulting in new structures quickly with desired properties from bioactive compounds. ${ }^{4}$ The corresponding studies in early times presented many good examples by applying activated molecules, which can enable $\mathrm{C}-\mathrm{C}$ bond cleavage easier. ${ }^{5,6}$ However, selective cleavage of inert $\mathrm{C}-\mathrm{C}$ bond is always a tough task for chemists due to the large bond dissociation energy (BDE). Recent efforts use transition metal catalysts in a heterolysis manner generally limited to strained ring compounds. $.^{3 \mathrm{e}-\mathrm{h}, 7} \mathrm{Be}-$ sides, homolysis methods involving radical intermediates can lead to the scission of inert $\mathrm{C}-\mathrm{C}$ bonds and may overcome the strict substrate limitation, suggesting new synthetic directions. ${ }^{8}$

As a kind of core organic chemicals, alcohols are readily accessible radical precursors, which can lead to the consequently C-C bond cleavage through beta-scission. However, the direct formation of alkoxy radical from alcohol is a big challenge, because the high $\mathrm{BDE}$ of $\mathrm{O}-\mathrm{H}$ bond $(\sim 105 \mathrm{kcal} / \mathrm{mol})$ make the corresponding homolysis cleavage difficult to achieve; and the relative low BDE of $\mathrm{sp}^{3} \mathrm{C}-\mathrm{H}$ bonds $(92.3-101 \mathrm{kcal} / \mathrm{mol}$ ) on the alcohol results in selectivity problems. ${ }^{9}$ To handle these issues, pioneer studies usually transform $\mathrm{O}-\mathrm{H}$ to weaker $\mathrm{O}-\mathrm{X}$ bonds, such as $\mathrm{O}-$ $\mathrm{NO} ;{ }^{5 \mathrm{a}}$ or use strained alcohols. ${ }^{8}$ Illustrated by these discoveries, (a) Previous work

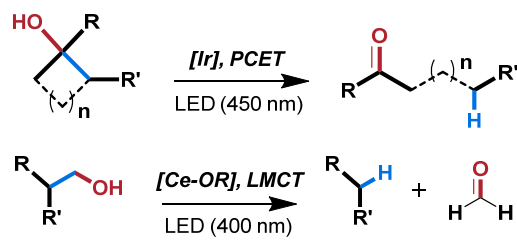

(b) This work: Iron catalyzed transformation of tertiary, secondary, and primary alcohols

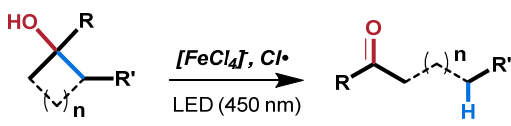

Figure 1. Deconstruction/hydrogenation of alcohols with different photocatalysts

various methods for the defunctionalization of cycloalkanols have been achieved recently, though restricted to strained substrates. ${ }^{8}$ In 2016, Knowles and coworkers reported the first C-C scission of unstrained tertiary alcohols through a proton-coupled electron transfer (PCET) pathway by using an Ir photocatalyst. ${ }^{10 a}$ An improved study was reported by the same group in 2019, which can be applied to secondary alcohols and even some special primary alcohols (Figure 1a). ${ }^{10 \mathrm{~b}}$ These two reports show general procedures for the deconstruction/hydrogenation of alcohols to produce the thermodynamically unfavored ketones/aldehydes, which can be applied to transform polycyclic nature products. In addition, limiting to tertiary alcohols, some other deconstructive functionalization, such as allylation ${ }^{11}$, halogenation ${ }^{12}$, and arylation ${ }^{13}$, can also be achieved by applying different photocatalyst systems. Besides, the Zuo group ${ }^{14}$ developed a Ce (III) improved photocatalysis system to enable the deconstructive amination and alkylation of both tertiary, secondary and primary alcohols, applying ditert-butyl azodicarboxylate (DBAD) and electron-deficient olefines as radical acceptors, respectively. The elegant catalyst system is performed through a ligand to metal charge transfer (LMCT) procedure of Ce-O species and shows great potentials for organic synthesis. However, only several examples of deconstruction/hydrogenation reactions were reported, showing dehydroxymethylation products through relatively stable radical intermediates (Figure 1a). ${ }^{14 \mathrm{c}}$ Until now, only the Ir photocatalyst has been discovered for the general deconstruction/hydrogenation reactions of alcohols. ${ }^{10}$ Obviously, for the development of various deconstruction/functionalization reactions of alcohols, including deconstruction/hydrogenation reactions, new systems with different catalytic activities and pathways are highly desired. 
Table 1. Selected results of optimization study ${ }^{a}$

\begin{tabular}{|c|c|c|}
\hline HO Ph & $\begin{array}{c}\mathrm{FeCl}_{3}(10 \mathrm{~mol} \%) \\
\operatorname{TBACl}^{2}(20 \mathrm{~mol} \%) \\
\operatorname{TRIP}_{2} \mathrm{~S}_{2}(20 \mathrm{~mol} \%)\end{array}$ & \\
\hline 1 & $\begin{array}{c}\text { collidine ( } 1 \text { equiv.) } \\
0.1 \mathrm{MDCE} \\
\text { blue LEDs, a.t, } 24 \mathrm{~h}\end{array}$ & 1a \\
\hline entry & condition changes & yield $\%{ }^{b}$ \\
\hline 1 & No change & 54 \\
\hline 2 & Without base & 14 \\
\hline 3 & 2,6-lutidine as base & 43 \\
\hline 4 & $\mathrm{PBu}_{4}^{+}(\mathrm{MeO})_{2} \mathrm{POO}^{-}$as base & 0 \\
\hline 5 & $\mathrm{PBu}_{4}^{+}(\mathrm{PhO})_{2} \mathrm{POO}^{-}$as base & trace \\
\hline 6 & TBACl (30 mol\%) & 51 \\
\hline 7 & TBACl (10 mol\%) & 45 \\
\hline 8 & Without TBACl & 26 \\
\hline 9 & $400 \mathrm{~nm}$ LED & trace \\
\hline 10 & $365 \mathrm{~nm}$ LED & 0 \\
\hline 11 & Without $\mathrm{FeCl}_{3}$ & 0 \\
\hline 12 & Without LED & 0 \\
\hline 13 & $48 \mathrm{~h}$ & 75 \\
\hline 14 & $60 \mathrm{~h}$ & $88\left(81^{c}\right)$ \\
\hline
\end{tabular}

${ }^{a}$ Reaction conditions: $1(0.2 \mathrm{mmol}), \mathrm{FeCl}_{3}(0.02 \mathrm{mmol}, 10 \mathrm{~mol} \%)$, TBACl (0.04 mmol, $20 \mathrm{~mol} \%)$, TRIP $_{2} \mathrm{~S}_{2}(0.04 \mathrm{mmol}, 20 \mathrm{~mol} \%)$, 2,4,6-collidine ( $0.2 \mathrm{mmol}, 1$ equiv.), and 1,2-dichloroethane (DCE $2 \mathrm{~mL}$ ) were irradiated with blue LEDs under $\mathrm{N}_{2}$ for $24 \mathrm{~h} .{ }^{b}$ Determined by ${ }^{1} \mathrm{H}$ NMR analysis using 1,1,2,2-tetrachloroethane as an internal standard. ${ }^{c}$ Isolated yield.

Our interests in C-C bond cleavage led us to search for practical catalysts to develop the selective deconstruction/functionalization methods for readily available chemicals. Environmentally friendly and inexpensive iron is one of the most abundant metals on the earth. ${ }^{15}$ Early studies show the potentials of iron salts to act as photocatalysts under visible light. ${ }^{16}$ In addition, some recent articles published by $\mathrm{Jin}^{17}$, Jiang ${ }^{18 a}$, Zeng ${ }^{18 b}$, and Rovis ${ }^{19}$ presented the photocatalytic abilities of iron compounds on oxidative and alkylative transformations. Herein, we report an unpresented redox neutral photocatalysis method to enable the deconstruction/hydrogenation reaction of alcohols through C-C single bond cleavage, applying an iron salt as the photocatalyst (Figure 1b). The simple and inexpensive catalyst system can transform both the tertiary, secondary, and primary alcohols with good functional group tolerance under visible light, illustrating new possibilities for the selective transformation of aliphatic alcohols.

1-Phenyl cyclohexanol is chosen as the substrate for the initial optimization study. Various conditions are tried (See Supporting Information for details) and selected results are listed in Table 1. When the combination of $\mathrm{FeCl}_{3}$, tetrabutylammonium chloride (TBACl), bis(2,4,6-triisopropyl phenyl) disulfide ( $\left.\mathrm{TRIP}_{2} \mathrm{~S}_{2}\right)$, and 2,4,6-collidine are applied, moderate yield of the corresponding $\mathrm{C}-\mathrm{C}$ bond cleavage product 1a is observed (entry 1). Base is found to be an essential factor for the performance of the reaction, and the condition in the absence of base leads to low product yield of $14 \%$ (entry 2). In addition, 2,6-lutidine results in a lower out- come as compare to 2,4,6-collidine (entry 3). While tetrabutylphosphonium phosphates, which present the best results for the Ir photocatalysis system ${ }^{11}$, give no conversion (entry 4) or trace amount of product (entry 5). The application of a different amount of $\mathrm{TBACl}$ changes the mole ratio of $\mathrm{Fe}$ and chloride ions and influences the reaction yields. The best combination is $10 \mathrm{~mol} \%$ of $\mathrm{FeCl}_{3}$ and $20 \mathrm{~mol} \%$ of $\mathrm{TBACl}$, which equals to a 1: $5 \mathrm{~mole}$ ratio of $\mathrm{Fe}$ and $\mathrm{Cl}$ (entry 1); higher or lower $\mathrm{Fe} / \mathrm{Cl}$ ratios lead to inferior outcomes (entries 6-8, see Supporting Information for details). In addition, testing of LEDs with shorter wavelength result in trace or no conversion (entries 9 and 10). Control experiments without $\mathrm{FeCl}_{3}$ or LED result in no product (entries 11 and 12), indicating an iron-catalyzed photocatalysis procedure of the reaction. Longer reaction time is helpful for the performance of the reaction (entry 13), a good isolated yield of $1 \mathrm{a}$ can be obtained after $60 \mathrm{~h}$ (entry 14).

With the optimized results, we begin to study the substrate scope (Scheme 1). Tertiary alcohols are tested firstly. Cyclohexanols with different phenyl substitutes on the alfa position show good reactivity, leading to moderate to good isolated yields of the desired products (1-9). Interestingly, electron effects on the benzene rings show little influence to the reaction and both electrondonating and withdrawing groups are well tolerated. The alcohols with seven and twelve-membered rings also react successfully, transforming to the ring-opening products in $64 \%$ and $53 \%$ isolated yields, respectively (10 and $\mathbf{1 1}$ ). In addition, the linear alcohol 12 also performs well and a $63 \%$ yield of the ketone product is observed. With para-methoxyphenyl group (PMP) adjacent to the hydroxyl group, cyclic alcohols with different ring sizes can transform to the corresponding ketone products with moderate to outstanding yields (13-18). Electron-rich (16) and deficient groups (17 and 18) on the rings do not disturb the reaction. However, 1methylcyclohexanol (19) shows inferior reactivity than other substrates and leads to low product yield even after a longer reaction time. Interestingly, 1-benzoylcyclohexanol (20) acts as a good substrate, of which the selective $\mathrm{C}-\mathrm{C}$ bond cleavage results in good yields of cyclohexanone and benzaldehyde, retaining the ring structure. Further substrate investigation involves primary and secondary alcohols. The reaction enables the dehydroxymethylation of primary alcohols through alfa-heteroatom-stabled radical fragments (21-24). For secondary alcohols, such as bridged (25), 2-substituted (26-29), and four-membered ring (30) substrates, moderate to excellent yields are observed, showing the generality of the reaction conditions. Even simple cycloalkanol bearing no substitute (31) can proceed with the ring opening procedure, though a lower yield is observed. Delightfully, the model compound for the lignin degradation study (32) and the similar substrates substituted with different heteroatoms ( $\mathbf{3 3}$ and $\mathbf{3 4}$ ) react smoothly under the reaction conditions, generating the corresponding $\mathrm{C}-\mathrm{C}$ bond cleavage products in good to outstanding yields. Next, we apply the reaction to the nature-originated alcohols, to generate the selective deconstruction/ hydrogenation products that partially reserve the corresponding complex structures. The relatively simple substrates, such as (-)-Nopol (35), isoborneol (36), and the cyclic glucose derivative (37), transform to the target products successfully. Furthermore, complex polycyclic alcohols, including testosterone (38), nandrolone (39), estradiol benzoate (40), 7-methyl testosterone (41), and cholesterol (42), show good performance for the isomerization transformation, 

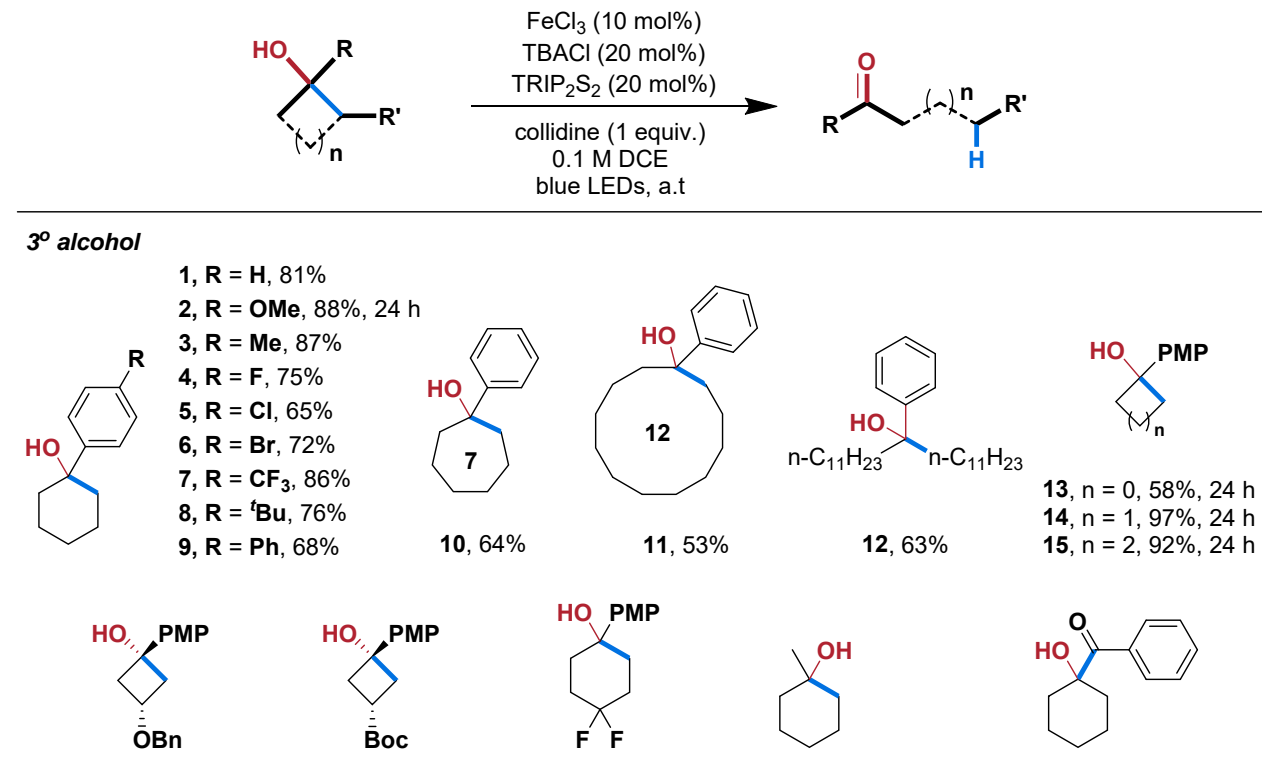

16, trans: cis $=88: 1217$, trans: cis $=85: 15 \quad 18,73 \%, 24 \mathrm{~h} \quad 19,31 \%^{\mathrm{a}}, 96 \mathrm{~h} \quad 20$, cyclohexanone, $81 \%^{\mathrm{a}}$ $86 \%, 24 \mathrm{~h} \quad 79 \%, 24 \mathrm{~h} \quad$ benzaldehyde, $90 \%^{\mathrm{a}}$
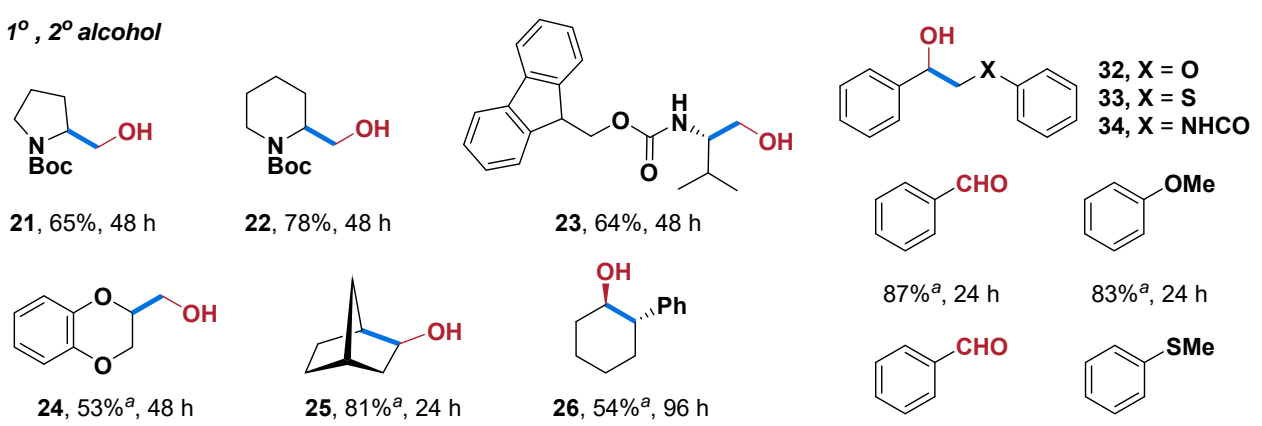

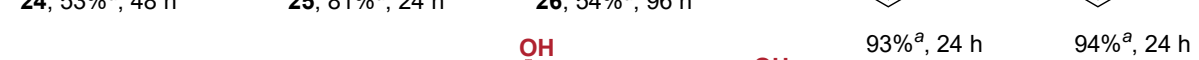
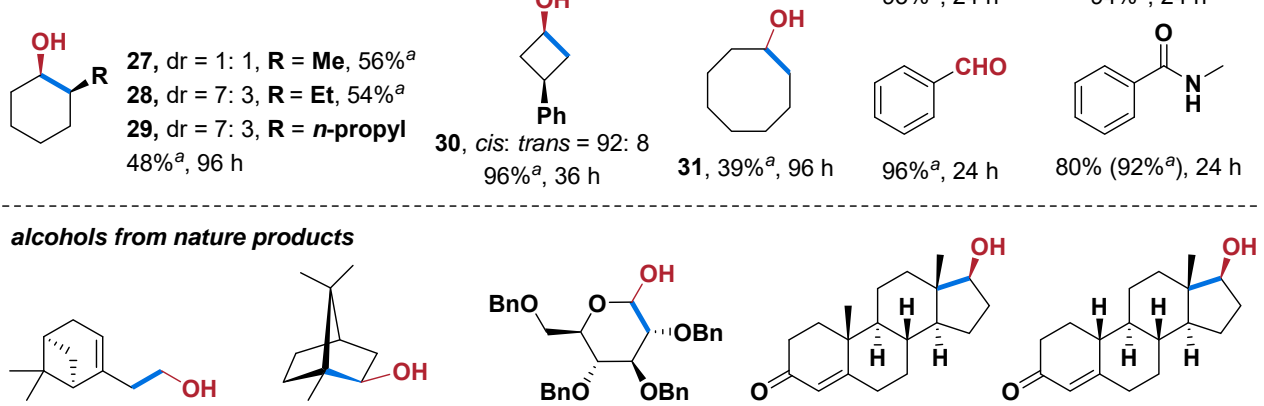

$35,42 \%\left(67 \%^{a}\right) \quad 36,80 \%, d r=5: 1,24 h \quad 37, \alpha: \beta=1: 1,91 \% \quad 38,94 \%, d r=1.3: 1 \quad 39,91 \%, d r=1.1: 1$

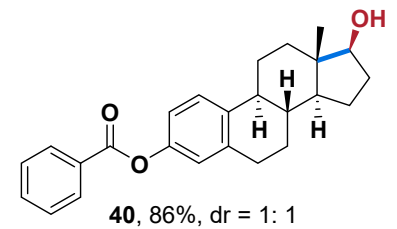

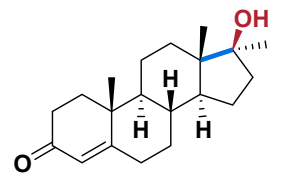

41, $96 \%, d r=1.4: 1$

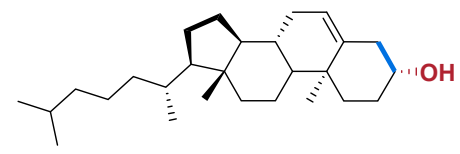

42, $67 \%$

Scheme 1. Substrate Scope. Reaction conditions: alcohol (0.2 mmol), $\mathrm{FeCl}_{3}(0.02 \mathrm{mmol}, 10 \mathrm{~mol} \%), \mathrm{TBACl}(0.04 \mathrm{mmol}, 20 \mathrm{~mol} \%)$, $\mathrm{TRIP}_{2} \mathrm{~S}_{2}(0.04 \mathrm{mmol}, 20 \mathrm{~mol} \%), 2,4,6$-collidine $\left(0.2 \mathrm{mmol}, 1\right.$ equiv.), blue LEDs $(450 \mathrm{~nm}), \mathrm{N}_{2}$ atmosphere, 60 h. Isolated yields are reported unless otherwise noted. ${ }^{a}$ Determined by GC-MS analysis using dodecane as an internal standard due to volatility.

producing the corresponding ring-opening products in moderate to excellent isolated yields. The optimized reaction conditions are efficient enough for various substrates, generally no change is required except the reaction time.
Photocatalysis usually suffers from small reaction scale, because the light intensity will be sharply decreased in the solvent. ${ }^{20}$ The large-scale light-promoted reactions often require the application of relatively complex equipment, to perform the reaction in a 
flow chemistry way. ${ }^{21}$ To test the performance of the large-scale reaction under simple irradiation conditions, we set up a $2 \mathrm{mmol}-$ scale reaction using testosterone $(576 \mathrm{mg}$ ) as the substrate (Figure 2 ). Though the conversion speed is relatively slow under the optimized conditions, a satisfactory isolated yield of the desired product $(76 \%, 438 \mathrm{mg})$ can be obtained, indicating the practical potential of the reaction using simple LED equipment.

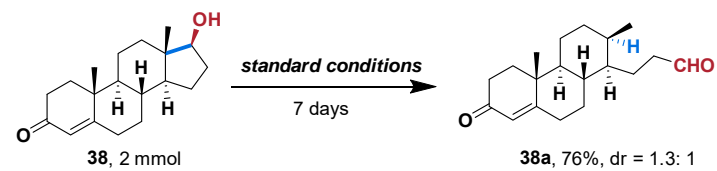

Figure 2. Large scale reaction

During the optimization study, we find the reaction may proceed through a chlorine radical involved mechanism, a different pathway as compared to the reported procedures. ${ }^{10,14}$ The condition screening study (see Table 1 and Supporting Information for details) already shows the essential role of chloride anion. To further confirm this, we set some control experiments as shown in Table 2. DCE is changed to the chloro-free $\mathrm{MeCN}$ to rule out the influence of the solvent. When the reaction applies $\mathrm{Fe}(\mathrm{OTf})_{3}$ without TBACl, no conversion is observed (entry 1). Alternatively, $\mathrm{FeCl}_{3}$ leads to a $54 \%$ yield of the product (entry 2). Addition of $20 \mathrm{~mol} \%$ of TBACl, which presents a 1: 5 ratio of $\mathrm{Fe}$ (III) and $\mathrm{Cl}$ anion, increases the outcome to $67 \%$ (entry 3 ). With the same Fe: $\mathrm{Cl}$ ratio, changing of $\mathrm{FeCl}_{3}$ to $\mathrm{Fe}(\mathrm{OTf})_{3}$ results in a similar product yield of $73 \%$ (entry 4 ). These results highlight the role of chloride anion as an indispensable part of the catalytic system.

Table 2. Reaction performances with/without chloride

\begin{tabular}{|c|c|c|c|}
\hline \multirow{3}{*}{$\underbrace{\text { EO }}_{1}$} & \multirow{2}{*}{\multicolumn{2}{|c|}{$\begin{array}{c}\text { [Fe] (10 mol\%) } \\
\text { TRIP }_{2} \mathrm{~S}_{2} \text { (20 mol\%) } \\
\text { collidine (1 equiv.) } \\
0.1 \mathrm{M} \mathrm{MeCN} \\
\text { blue LEDs, a.t., } 60 \mathrm{~h}\end{array}$}} & \multirow[b]{2}{*}{$1 a$} \\
\hline & & & \\
\hline & {$[\mathrm{Fe}]$} & TBACl (mol\%) & Yield $(\%)^{a}$ \\
\hline 1 & $\mathrm{Fe}(\mathrm{OTf})_{3}$ & 0 & 0 \\
\hline 2 & $\mathrm{FeCl}_{3}$ & 0 & 54 \\
\hline 3 & $\mathrm{FeCl}_{3}$ & 20 & 67 \\
\hline 4 & $\mathrm{Fe}(\mathrm{OTf})_{3}$ & 50 & 73 \\
\hline
\end{tabular}

Reaction conditions: 1 ( $0.2 \mathrm{mmol}, 1$ equiv.), iron salt (10 $\mathrm{mol} \%)$, $\mathrm{TRIP}_{2} \mathrm{~S}_{2}(20 \mathrm{~mol} \%), 2,4,6$-collidine (1 equiv.), and $\mathrm{MeCN}(2 \mathrm{~mL})$ are irradiated with blue LEDs under $\mathrm{N}_{2}$ for 60 h. ${ }^{a}$ Determined by ${ }^{1} \mathrm{H}$ NMR analysis using 1,1,2,2-tetrachloroethane as an internal standard.

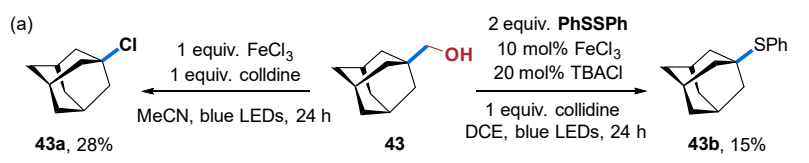

(b)

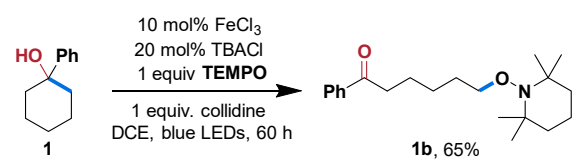

Figure 3. Radical trapping experiments
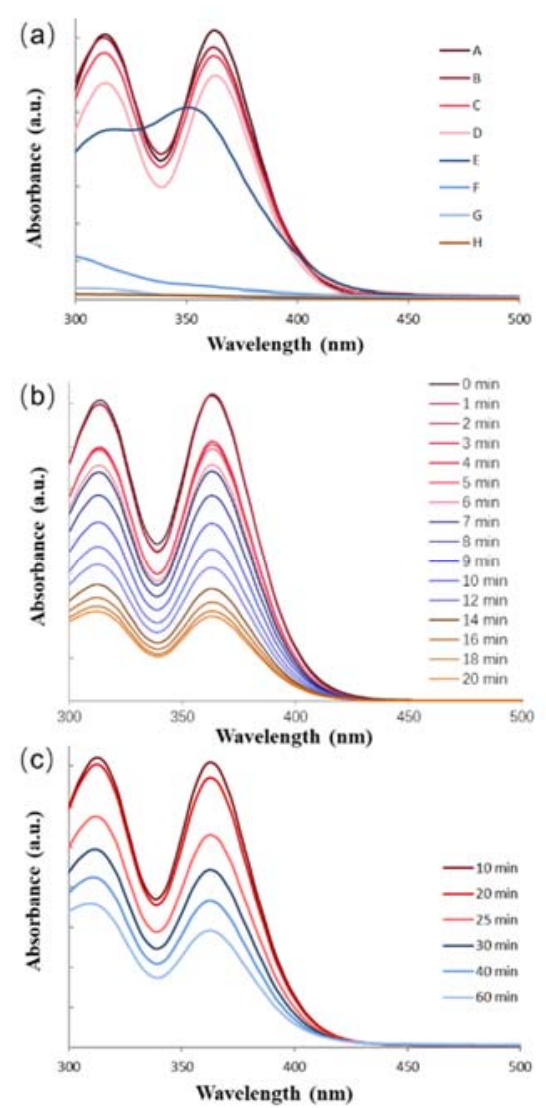

Figure 4. Investigation of UV-vis absorption of iron salts. Concentration of Fe: $0.1 \mathrm{mmol} / \mathrm{L}$ in DCE. (a) UV-vis spectra of different combinations with iron. $\mathrm{A}: \mathrm{FeCl}_{3}$ and $\mathrm{TBACl}(1: 2)$; $\mathrm{B}$ : $\mathrm{FeCl}_{3}, \mathrm{TBACl}$ and collidine (1: 2: 1); $\mathrm{C}: \mathrm{FeCl}_{3}, \mathrm{TBACl}, \mathbf{1}$ and collidine (1: 2: 10: 10) ; D: $\mathrm{Fe}(\mathrm{OTf})_{3}$ and TBACl (1: 5); $\mathrm{E}: \mathrm{FeCl}_{3}$; $\mathrm{F}$ : $\mathrm{FeCl}_{2}$ and $\mathrm{TBACl}(1: 3)$; $\mathrm{G}: \mathrm{FeCl}_{2} ; \mathrm{H}: \mathrm{Fe}(\mathrm{OTf})_{3}$; (b) UV-vis spectra of mixed solvent of $\mathrm{FeCl}_{3}$ and TBACl (1:2) after different irradiation time (0-20 min) with blue LED (450 nm); (c) UV-vis spectra of mixed solvent of $\mathrm{FeCl}_{3}, \mathrm{TBACl}, 1$ and collidine (1: 2: 10: 10) after different irradiation time (10-60 min) with blue LED $(450 \mathrm{~nm})$.

Next, a chlorine radical trapping reaction applying 1adamantanylmethanol and stoichiometric $\mathrm{FeCl}_{3}$ in the absence of $\mathrm{TRIP}_{2} \mathrm{~S}_{2}$ is set up, leading to the corresponding product 1chloroadamantane in $28 \%$ yield (Figure $3 \mathrm{a}$, left). $\mathrm{PhS} \bullet$ was also trapped using stoichiometric PhSSPh (Figure 3a, right). In addition, TEMPO is applied as a radical trap to stabilize the deconstruction intermediate of 1-phenylcyclohexanol (1), presenting the terminal carbon radical-trapped product successfully (Figure $3 b$ ). Light on/off experiment is performed, and no reaction is observed without LED, which rules out the chain mechanism (See Supporting Information for details). UV-vis spectra of iron salt with $\mathrm{TBACl}$, collidine and alcohol $\mathbf{1}$ in different combinations are also detected, as shown in Figure 4a. Interestingly, all the combinations containing TBACl show typical absorption peaks of $\left[\mathrm{FeCl}_{4}\right]^{-}$ ,${ }^{22}$ even in the alcohol and collidine-included case (Figure 4a, C). The time- resolved UV-vis spectra of $\mathrm{FeCl}_{3}$ and TBACl after irradiation with blue light are detected, only absorption peaks of $\left[\mathrm{FeCl}_{4}\right]^{-}$are observed (Figure $4 \mathrm{~b}$ ). Irradiation for a longer time leads to weaker absorption peaks, probably due to the formation of $\mathrm{Cl} \cdot$ and $\left[\mathrm{FeCl}_{3}\right]^{-}$from $\left[\mathrm{FeCl}_{4}\right]^{-}$through an LMCT process, which decreases the $\left[\mathrm{FeCl}_{4}\right]^{-}$concentration; since $\mathrm{FeCl}_{2}$ and the 
corresponding complex with $\mathrm{TBACl}$ show very weak absorption in DCE (Figure $4 a, F$ and $\mathrm{G}$ ). Further time progression UV-vis spectra of the solution of $\mathrm{FeCl}_{3}, \mathrm{TBACl}, 1$ and collidine (1: 2: 10: 10) after irradiation with blue light only show peaks of $\left[\mathrm{FeCl}_{4}\right]^{-}$, no new peak is observed even after a long time of irradiation (Figure 4c). The observation excludes the possibility of the formation of a Fe-alkoxyl species under the reaction conditions, ${ }^{24 a}$ which can generate the alkoxy radical through an LMCT process.

Table 3. Competition study of benzylic $\mathrm{C}-\mathrm{H}$ bond activation and $\mathrm{C}-\mathrm{C}$ bond activation

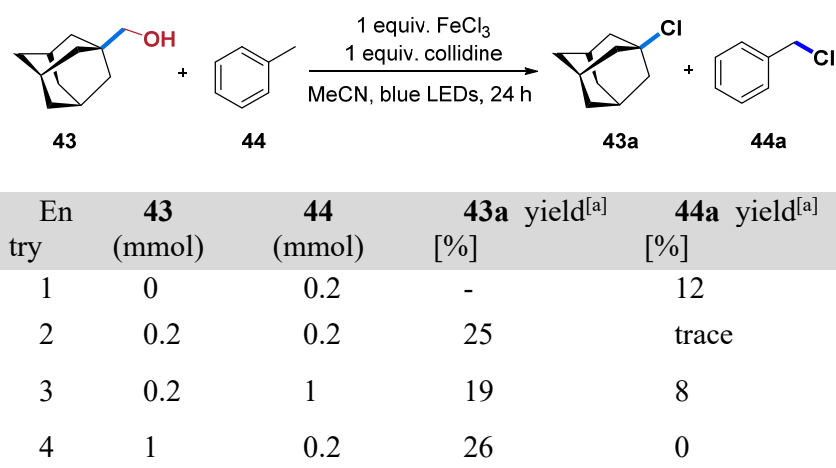

Reaction conditions: $\mathbf{4 3}, \mathbf{4 4}, \mathrm{FeCl}_{3}(0.2 \mathrm{mmol}, 1$ equiv. $)$, 2,4,6collidine (1 equiv.), and $\mathrm{MeCN}(2 \mathrm{~mL})$ are irradiated with blue LEDs under $\mathrm{N}_{2}$ for $24 \mathrm{~h}$. [a] Determined by ${ }^{1} \mathrm{H}$ NMR analysis using 1,1,2,2-tetrachloroethane as an internal standard.

Due to the high energy of $\mathrm{Cl} \cdot$, and the relatively low BDE of C$\mathrm{H}$ bonds as compared to the $\mathrm{O}-\mathrm{H}$ bond, the unusual selectivity of the reaction is an important issue needs to be studied. To clarify the selectivity problem, competition reactions of different ratios (in mol) of 1-adamantanylmethanol and toluene in the presence of 1 equiv. of $\mathrm{FeCl}_{3}$ were performed, as shown in Table 3. In the absence of 1-adamantanylmethanol, 12\% yield of benzyl chloride was generated (entry 1), which is also a direct evidence of the formation of chlorine radical. However, when the same amount of 1-adamantanylmethanol was applied together with toluene, only trace of benzyl chloride was observed; while the C-C bond cleavage product 1 -chloroadamantane was generated in $25 \%$ yield (entry 2). The outcome of benzoyl chloride was low even under the condition of applying excess of toluene and 1 equiv. of 1adamantanylmethanol, leading to much higher yield of 1chloroadamantane (entry 3). When excess of 1adamantanylmethanol was applied, the transformation of toluene was fully restrained (entry 4). The addition of 1adamantanylmethanol surely doesn't change the weak BDE of benzylic C-H bond $(\sim 90 \mathrm{kcal} / \mathrm{mol})$. A reasonable explanation for the surprising result is the quickly formation of the adduct of $\mathrm{Cl} \bullet$ and the oxygen atom of the alcohol, due to the electrophilic property of chlorine radical. ${ }^{24}$ Thus, the HAT course can be restricted on the $\mathrm{O}-\mathrm{H}$ bond with the assistant of collidine, which can decrease the strength of $\mathrm{O}-\mathrm{H}$ bond ${ }^{10}$ and absorb the subsequently formed $\mathrm{HCl}$.

Based on the above investigation, a mechanism is proposed in Figure 5. $\left[\mathrm{FeCl}_{4}\right]^{-}$is excited by blue light to form a chlorine radical through an LMCT process. ${ }^{24}$ The electrophilic Cl can easily generate an adduct with the oxygen atom of the alcohol, which then forms the alkoxy radical with the assistant of collidine. ${ }^{10,24}$ Further beta-scission of the alkoxy radical leads to the ringopening radical, which generates the target product and $\mathrm{ArS} \bullet(\mathrm{Ar}$ $=2,4,6$-triisopropyl phenyl or $\mathrm{Ph}$ ) through HAT with the thiophenol $(\mathrm{ArSH}){ }^{25}$ Originally formed from a disulfide (TRIP $2 \mathrm{~S}_{2}$ or $\mathrm{Ph}_{2} \mathrm{~S}_{2}$ ), ArS• can oxidize Fe (II) to Fe (III), ${ }^{22 \mathrm{a}, 26}$ regenerating the
$\left[\mathrm{FeCl}_{4}\right]^{-}$species and $\mathrm{ArS}^{-}$. The resulting $\mathrm{ArS}^{-}$species traps a proton to form the thiophenol (ArSH, $\mathrm{Ar}=2,4,6$-triisopropyl phenyl, was detected by GC-MS) again.

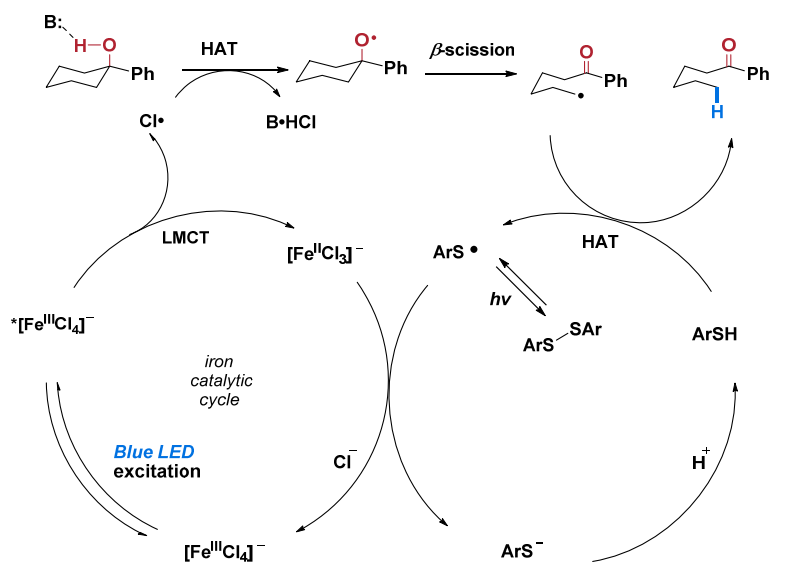

Figure 5. Proposed mechanism

In conclusion, we develop a visible light photocatalysis procedure to enable the redox-neutral deconstruction/hydrogenation of alcohols, forming single $\mathrm{C}-\mathrm{C}$ bond cleavage products. Applying inexpensive and earth-abundant iron salts as the catalysts, the reaction enjoys a good functional group tolerance and a wide substrate scope. Both tertiary, secondary, and primary alcohols can act as suitable substrates. The tested cycloalkanols with small and large rings all transform to the ring-opening products successfully. Furthermore, the alcohols from natural product sources can smoothly perform the transformation, generating the target compounds selectively, with the resting structure untouched. The mechanism investigation indicates a new reaction pathway, which is promoted by the chlorine radical generated from $\left[\mathrm{FeCl}_{4}\right]^{-}$. The research highlights the potential of simple iron salts as efficient photocatalysts for unique transformations. Further studies of developing iron-catalyzed deconstruction/functionalization reactions through photocatalysis are underway.

\section{ASSOCIATED CONTENT}

\section{Supporting Information}

The Supporting Information is available.

\section{AUTHOR INFORMATION}

\section{Corresponding Author}

Peng Hu - Lehn Institute of Functional Materials, School of Chemistry, Sun Yat-Sen University, Guangzhou 510006, China; orcid.org/0000-0001-7864-3514;

Email: hupeng8@mail.sysu.edu.cn

\section{Authors}

Wei Liu - Lehn Institute of Functional Materials, School of Chemistry, Sun Yat-Sen University, Guangzhou 510006, China

Qiang Wu - Lehn Institute of Functional Materials, School of Chemistry, Sun Yat-Sen University, Guangzhou 510006, China Miao Wang - Lehn Institute of Functional Materials, School of Chemistry, Sun Yat-Sen University, Guangzhou 510006, China Yahao Huang - Lehn Institute of Functional Materials, School of Chemistry, Sun Yat-Sen University, Guangzhou 510006, China

\section{Author Contributions}


$\dagger$ W.L. and Q.W. contributed equally to this work.

\section{Notes}

The authors declare no competing financial interest.

\section{ACKNOWLEDGMENT}

We would like to acknowledge financial support from the Department of Science and Technology of Guangdong Province (no. 2019QN01L151), the National Natural Science Foundation of China (no. 21821003), and Sun Yat-Sen University.

\section{REFERENCES}

(1) (a) Carreira, E. M.; Kvaerno, L. Classics in Stereoselective Synthesis; Wiley-VCH: Weinheim, 2009. (b) Baran, P. S.; Maimone, T. J.; Richter, J. M. Total Synthesis of Marine Natural Products Without Using Protecting Groups. Nature 2007, 446, 404-408. (c) Trost, B. M. The Atom EconomyA Search for Synthetic Efficiency. Science 1991, 254, 1471-1477.

(2) (a) Lovering, F.; Bikker, J.; Humblet, C. Escape from Flatland: Increasing Saturation as an Approach to Improving Clinical Success. J. Med. Chem. 2009, 52, 6752-6756. (b) Weissermel, K.; Arpe H.-J. Industrial Organic Chemistry ( $4^{\text {th }}$ ed.), Wiley-VCH: Weinheim, 2003.

(3) (a) Roque, J. B.; Kuroda, Y.; Göttemann, L. T.; Sarpong, R. Deconstructive Diversification of Cyclic Amines. Nature 2018, 564, 244-248. (b) Jones, W. D. The Fall of the C-C Bond. Nature 1993, 364, 676-677. (c) Chen, F.; Wang, T.; Jiao, N. Recent Advances in Transition-MetalCatalyzed Functionalization of Unstrained Carbon-Carbon Bonds. Chem. Rev. 2014, 114, 8613-8661. (d) Marek, I.; Masarwa, A.; Delaye, P.-O.; Leibeling, M. Selective Carbon-Carbon Bond Cleavage for the Stereoselective Synthesis of Acyclic Systems. Angew. Chem., Int. Ed. 2015, 54, 414-429. (e) Souillart, L.; Cramer, N. Catalytic C-C Bond Activations via Oxidative Addition to Transition Metals. Chem. Rev. 2015, 115, 94109464. (f) Fumagalli, G.; Stanton, S.; Bower, J. F. Recent Methodologies That Exploit C-C Single-Bond Cleavage of Strained Ring Systems by Transition Metal Complexes. Chem. Rev. 2017, 117, 9404-9432. (g) Murakami, M.; Ishida, N. Potential of Metal-Catalyzed C-C Single Bond Cleavage for Organic Synthesis. J. Am. Chem. Soc. 2016, 138, 1375913769. (h) Aïssa, C. Transition-Metal-Catalyzed Rearrangements of Small Cycloalkanes: Regioselectivity Trends in $\beta$-Carbon Elimination Reactions. Synthesis 2011, 2011, 3389-3407.

(4) Böhm, H.-J.; Flohr, A.; Stahl, M. Scaffold Hopping. Drug Discovery Today Technol. 2004, 1, 217-224.

(5) (a) Robinson, C. H.; Gnoj, O.; Mitchell, A.; Wayne, R.; Townley, E.; Kabasakalian, P.; Oliveto, E. P.; Barton, D. H. R. The Photolysis of Organic Nitrites. II. Synthesis of Steroidal Hydroxamic Acids. J. Am. Chem. Soc. 1961, 83, 1771-1772. (b) Canovas, A.; Bonet, J.-J. A Norrish Type I Cleavage in the Photolysis of a Steroidal $\alpha, \beta$-Unsaturated $\delta$-Lactone. Photochemical Reactions. XIV [1]. Helv. Chim. Acta. 1980, 63, 23902392. (c) Boivin, J.; Fouquet, E.; Zard, S. Z. Ring Opening Induced by Iminyl Radicals Derived from Cyclobutanones: New Aspects of Tin Hydride Cleavage of S-phenyl Sulfenylimines. J. Am. Chem. Soc. 1991, 113, 1055-1057. (d) Boivin, J.; Fouquet, E.; Zard, S. Z. Iminyl radicals: part II. ring Opening of Cyclobutyl- and Cyclopentyliminyl Radicals. Tetrahedron 1994, 50, 1757-1768. (e) Boivin, J.; Fouquet, E.; Zard, S. Z. Zard. Iminyl radicals: Part III. Further Synthetically Useful Sources of Iminyl Radicals. Tetrahedron 1994, 50, 1769-1776. (f) Boivin, J.; Fouquet, E.; Zard, S. Z. A New and Synthetically Useful Source of Iminyl Radicals. Tetrahedron Lett. 1991, 32, 4299-4302.

(6) For selected recent examples, see (a) Thompson, M. S.; Cui, W.; Reilly, J. P. Fragmentation of Singly Charged Peptide Ions by Photodissociation at $\lambda=157 \mathrm{~nm}$. Angew. Chem., Int. Ed. 2004, 43, 4791-4794. (b) Newman, C. A.; Resendiz, M. J. E.; Sczepanski, J. T.; Greenberg, M. M. Photochemical Generation and Reactivity of the 5,6-Dihydrouridin-6-yl Radical. J. Org. Chem. 2009, 74, 7007-7012. (c) Paul, R.; Greenberg, M. M. Independent Generation and Reactivity of Uridin-2'-yl Radical. J. Org. Chem. 2014, 79, 10303-10310. (d) Shi, Y.; Jiang, X.-L.; Tian, W.-S. Synthesis of 12,12'-azo-13,13'-diepi-Ritterazine N. J. Org. Chem. 2017, 82, 269-275. (e) Geoffroy, P.; Ressault, B.; Marchioni, E.; Miesch, M. Norrish-Prins Reaction as a Key Step in the Synthesis of $14 \beta$-Hydroxy-5 $\alpha$ (or $5 \beta$ or $\left.\Delta^{5,6}\right)$-Pregnane Derivatives. Steroids, 2011, 76, 1166-1175. (f) Drahl, M. A.; Manpadi, M.; Williams, L. J. C-C Fragmentation: Origins and Recent Applications. Angew. Chem. Int. Ed. 2013, 52, 11222-11251. (g) Zhang, J.; Li, Y.; Zhang, F.; Hu, C.; Chen, Y. Generation of Alkoxyl
Radicals by Photoredox Catalysis Enables Selective C( $\left.\mathrm{sp}^{3}\right)-\mathrm{H}$ Functionalization under Mild Reaction Conditions. Angew. Chem., Int. Ed. 2016, 55, 1872-1875. (h) Zhang, J.; Li, Y.; Xu, R.; Chen, Y. Donor-Acceptor Complex Enables Alkoxyl Radical Generation for Metal-Free C $\left(\mathrm{sp}^{3}\right)-\mathrm{C}\left(\mathrm{sp}^{3}\right)$ Cleavage and Allylation/Alkenylation. Angew. Chem., Int. Ed. 2017, 56, 12619-12623.

(7) (a) Xu, T.; Dermenci, A.; Dong, G. Transition Metal-Catalyzed C-C Bond Activation of Four-Membered Cyclic Ketones. Top. Curr. Chem. 2014, 346, 233-257. (b) Chen, P.-H.; Billett, B.; Tsukamoto, T.; Dong, G. "Cut and Sew" Transformations via Transition-Metal-Catalyzed CarbonCarbon Bond Activation. ACS Catal. 2017, 7, 1340-1360.

(8) (a) Wu, X.; Zhu, C. Recent Advances in Ring-Opening Functionalization of Cycloalkanols by C-C $\sigma$-Bond Cleavage. Chem. Rec. 2018, 18 , 587-598. (b) Yan, H.; Zhu, C. Recent Advances in Radical-Mediated Fluorination through $\mathrm{C}-\mathrm{H}$ and C-C Bond Cleavage. Sci. China: Chem 2017, 60, 214-222. (c) Wu, X.; Zhu, C. Recent Advances in RadicalMediated C-C Bond Fragmentation of Non-Strained Molecules. Chin. J. Chem. 2018, 37, 171-182. (d) Sivaguru, P.; Wang, Z.; Zanoni, G.; Bi, X. Cleavage of Carbon-Carbon Bonds by Radical Reactions. Chem. Soc. Rev. 2019, 48, 2615-2656. (e) Morcillo, S. P. Radical-Promoted C-C Bond Cleavage: A Deconstructive Approach for Selective Functionalization. Angew. Chem., Int. Ed. 2019, 58, 14044-14054. (f) Yu, X.-Y.; Chen, J.-R.; Xiao, W.-J. Visible Light-Driven Radical-Mediated C-C Bond Cleavage/Functionalization in Organic Synthesis. Chem. Rev. 2021, 121, 506561

(9) Blanksby, S. J.; Ellison, G. B. Bond Dissociation Energies of Organic Molecules. Acc. Chem. Res. 2003, 36, 255-263.

(10) (a) Yayla, H. G.; Wang, H.; Tarantino, K. T.; Orbe, H. S.; Knowels, R. R. Catalytic Ring-Opening of Cyclic Alcohols Enabled by PCET Activation of Strong O-H Bonds. J. Am. Chem. Soc. 2016, 138, 10794-10797. (b) Ota, E.; Wang, H.; Frye, N. L.; Knowels, R. R. A Redox Strategy for Light-Driven, Out-of-Equilibrium Isomerizations and Application to Catalytic C-C Bond Cleavage Reactions. J. Am. Chem. Soc. 2019, 141, $1457-$ 1462.

(11) Wang, J.; Huang, B.; Shi, C.; Yang, C.; Xia, W. Visible-LightMediated Ring-Opening Strategy for the Regiospecific Allylation/Formylation of Cycloalkanols. J. Org. Chem. 2018, 83, 9696-9706.

(12) (a) Wang, D.; Mao, J.; Zhu, C. Visible Light-Promoted Ring-Opening Functionalization of Unstrained Cycloalkanols via Inert C-C Bond Scission. Chem. Sci. 2018, 9, 5805-5809.

(13) (a) Huang, L.; Ji, T.; Rueping, M. Remote Nickel-Catalyzed CrossCoupling Arylation via Proton-Coupled Electron Transfer-Enabled C-C Bond Cleavage. J. Am. Chem. Soc. 2020, 142, 3532-3539. (b) Zhu, Y Zhang, Z.; Jin, R.; Liu, J.; Liu, G.; Han, B.; Jiao, N. DMSO-Enabled Selective Radical O-H Activation of 1,3(4)-Diols. Angew. Chem. Int. Ed. 2020, 59, 19851-19856.

(14) (a) Guo, J.; Hu, A.; Chen, Y.; Sun, J.; Tang, H.; Zuo, Z. Photocatalytic C-C Bond Cleavage and Amination of Cycloalkanols by Cerium(III) Chloride Complex. Angew. Chem. Int. Ed. 2016, 55, 15319-15322. (b) Hu, A.; Chen, Y.; Guo, J.-J.; Yu, N.; An, Q.; Zuo, Z. Cerium-Catalyzed Formal Cycloaddition of Cycloalkanols with Alkenes through Dual Photoexcitation. J. Am. Chem. Soc. 2018, 140, 13580-13585. (c) Zhang, K.; Chang, L.; An, Q.; Wang, X.; Zuo, Z. Dehydroxymethylation of Alcohols Enabled by Cerium Photocatalysis. J. Am. Chem. Soc. 2019, 141, 10556-10564.

(15) (a) Egorova, K. S.; Ananikov, V. P. Which Metals are Green for Catalysis? Comparison of the Toxicities of $\mathrm{Ni}, \mathrm{Cu}, \mathrm{Fe}, \mathrm{Pd}, \mathrm{Pt}, \mathrm{Rh}$, and $\mathrm{Au}$ Salts. Angew. Chem. Int. Ed. 2016, 55, 12150-12162. (b) Müller, J.; Bröring, M. In Iron Catalysis in Organic Chemistry: Reactions and Applications (Ed.: B. Plietker), Wiley-VCH, Weinheim, 2008, chap. 2, pp. 29-72. (16) (a) Magnuson, R. H.; Zulu, S.; T'Sai, W.-M.; Giering, W. P. Detection and Characterization of Radical Cations Resulting from the Oxidation of Methyl and Acetyl Iron Complexes. J. Am. Chem. Soc. 1980, 102, 6887-6888. (b) Brault, D.; Neta, P. Reactions of Iron Porphyrins with Methyl Radicals. J. Am. Chem. Soc. 1981, 103, 2705-2710. (c) Bartocci, C.; Maldotti, A.; Varani, G.; Battioni, P.; Carassiti, V.; Mansuy, D. Photoredox and Photocatalytic Characteristics of Various Iron MesoTetraarylporphyrins. Inorg. Chem. 1991, 30, 1255-1259. (d) Maldotti, A.; Amadelli, R.; Bartocci, C.; Carassiti, V.; Polo, G.; Varani, G. Photochemistry of Iron-Porphyrin Complexes. Biomimetics and Catalysis. Coord. Chem. Rev. 1993, 125, 143-154. (e) Weller, C.; Horn, S.; Herrmann, H. Photolysis of Fe(III)carboxylato Complexes: Fe(II) Quantum Yields and Reaction Mechanisms. J. Photochem. Photobiol. A. 2013, 268, 24-36.

(17) (a) Li, Z.; Wang, X.; Xia, S.; Jin, J. Ligand-Accelerated Iron Photocatalysis Enabling Decarboxylative Alkylation of Heteroarenes. Org. Lett. 2019, 21, 4259-4265. (b) Xia, S.; Hu, K.; Lei, C.; Jin, J. Intramolecular 
Aromatic C-H Acyloxylation Enabled by Ion Photocatalysis. Org. Lett. 2020, 22, 1385-1389.

(18) (a) Li, S.; Zhu, B.; Lee, R.; Qiao, B.; Jiang, Z. Visible Light-Induced Selective Aerobic Oxidative Transposition of Vinyl Halides Using a Tetrahalogenoferrate(III) Complex Catalyst. Org. Chem. Front. 2018, 5, 380385. (b) Zhang, Z.; Zhang, G.; Xiong, N.; Xue, T.; Zhang, J.; Bai, L.; Guo, Q.; Zeng, R. Oxidative $\alpha$-C-C Bond Cleavage of $2^{\circ}$ and $3^{\circ}$ Alcohols to Aromatic Acids with $\mathrm{O}_{2}$ at Room Temperature via Iron Photocatalysis. Org. Lett. 2021, 23, 2915-2920.

(19) Kang, Y. C.; Treacy, S. M.; Rovis, T. Iron-Catalyzed Photoinduced LMCT: A $1^{\circ} \mathrm{C}-\mathrm{H}$ Abstraction Enables Skeletal Rearrangements and C( $\left.\mathrm{sp}^{3}\right)$-H Alkylation. ACS Catal. 2021, 11, 7442-7449.

(20) Buzzetti, L.; Crisenza, G. E. M.; Melchiorre, P. Mechanistic Studies in Photocatalysis. Angew. Chem., Int. Ed. 2019, 58, 3730-3747.

(21) (a) H, A.; Guo, J.-J.; Pan, H.; Zuo, Z. Selective Functionalization of Methane, Ethane, and Higher Alkanes by Cerium Photocatalysis. Science 2018, 361, 668-672. (b) Laudadio, G.; Deng, Y.; van der Wal, K.; Ravelli, D.; Nuño, M.; Fagnoni, M.; Guthrie, D.; Sun, Y.; Noël, T. C( $\left.\mathrm{sp}^{3}\right)$-H Functionalizations of Light Hydrocarbons Using Decatungstate Photocatalysis in Flow. Science 2020, 369, 92-96. (c) Yan, H.; Song, J.; Zhu, S.; Xu, H.C. Synthesis of Acridinium Photocatalysts via Site-Selective C-H Alkylation. CCS Chem. 2021, 3, 317-325.

(22) (a) Rollick, K. L.; Kochi, J. K. Ligand Effects on the Reduction of Iron(III) Complexes by Alkyl Radicals. Formation of Alkyl Isocyanides and Chlorides from Cyanoiron(III) and Chloroiron(III) Species. Organometallics 1982, 1, 725-732. (b) Yoon, K. B.; Kochi, J. K. Ferric Iodide as a Nonexistent Compound. Inorg. Chem. 1990, 29, 869-874. (c) Abedi, A.; Safari, N.; Amani, V.; Khavasi, H. R. Synthesis, Characterization, Mechanochromism and Photochromism of $\left[\mathrm{Fe}(\mathrm{dm} 4 \mathrm{bt})_{3}\right]\left[\mathrm{FeCl}_{4}\right]_{2}$ and $\left[\mathrm{Fe}(\mathrm{dm} 4 \mathrm{bt})_{3}\right]\left[\mathrm{FeBr}_{4}\right]_{2}$, Along with the Investigation of Steric Influence on Spin State. Dalton Trans. 2011, 40, 6877-6885. (d) Cotton, S. A. Iron(III) Chloride and its Coordination Chemistry. J. Coord. Chem. 2018, 71, 3415-3443.

(23) (a) Kochi, J. K. Photolyses of Metal Compounds: Cupric Chloride in Organic Media. J. Am. Chem. Soc. 1962, 84, 2121-2127. (b) Shulpin, G. B.; Kats, M. M. Ferric Chloride Catalyzed Photooxidation of Alkanes by Air in Organic Solvents. React. Kinet. Catal. Lett. 1990, 41, 239-243. (c) Shul'pin, G. B.; Kats, M. M. Photochemical Oxidation of Saturated and Alkylaromatic Hydrocarbons by Atmospheric Oxygen in $\mathrm{CH}_{3} \mathrm{CN}$ or $\mathrm{CH}_{2} \mathrm{Cl}_{2}$ Solution, Catalyzed by Iron(III) Halides. Pet. Chem. 1991, 31, 647-656. (d) Shul'pin, G. B.; Nizova, G. V.; Kozlov, Y. N. Photochemical Aerobic Oxidation of Alkanes Promoted by Iron Complexes. New J. Chem. 1996, 20, 1243-1256.(e) Takaki, K.; Yamamoto, J.; Matsushita, Y.; Morii, H.; Shishido,T.; Takehira, K. Oxidation of Alkanes with Dioxygen Induced by Visible Light and $\mathrm{Cu}(\mathrm{II})$ and Fe(III) Chlorides. Bull. Chem. Soc. Jpn. 2003, 76, 393-398. (f) Takaki, K.; Yamamoto, J.; Komeyama, K. Kawabata, T.; Takehira, K. Photocatalytic Oxidation of Alkanes with Dioxygen by Visible Light and Copper(II) and Iron(III) Chlorides: Preference Oxidation of Alkanes over Alcohols and Ketones. Bull. Chem. Soc. Jpn. 2004, 77, 2251-2255.

(24) (a) Yang, Qi.; Wang, Y.-H.; Qiao, Y.; Gau, M.; Carroll, P. J.; Walsh, P. J.; Schelter, E. J. Photocatalytic C-H Activation and the Subtle Role of Chlorine Radical Complexation in Reactivity. Science 2021, 372, 847-852. (b) Mereshchenko, A. S., Olshin, P. K.; Myasnikova, O. S.; Panov, M. S.; Kochemirovsky, V. A., Skripkin, M. Y.; Moroz, P. N., Zamkov, M.; Tarnovsky, A. N. Ultrafast Photochemistry of Copper(II) Monochlorocomplexes in Methanol and Acetonitrile by Broadband Deep-UV-to-Near-IR Femtosecond Transient Absorption Spectroscopy. J. Phys. Chem. A 2016, 120, 1833-1844. (c) Mereshchenko, A. S.; Pal, S. K.; Karabaeva, K. E.; El-Khoury, P. Z.; Tarnovsky, A. N. Photochemistry of Monochloro Complexes of Copper(II) in Methanol Probed by Ultrafast Transient Absorption Spectroscopy. J. Phys. Chem. A 2012, 116, 2791-2799. (d) Gilbert, B. C.; Stell, J. K.; Peet, W. J.; Radford, K. J. Generation and Reactions of the Chlorine Atom in Aqueous Solution. J. Chem. Soc. Faraday Trans. 1988, 84, 3319-3330. (e) Jodkowski, J. T.; Rayez, M. T.; Rayez, J. C.; Bérces T.; Dóbé, S. Theoretical Study of the Kinetics of the Hydrogen Abstraction from Methanol. 2. Reaction of Methanol with Chlorine and Bromine Atoms. J. Phys. Chem. A 1998, 102, 9230-9243.

(25) (a) Bordwell, F. G.; Cheng, J.-P.; Harrelson, J. A. Homolytic Bond Dissociation Energies in Solution from Equilibrium Acidity and Electrochemical Data. J. Am. Chem. Soc. 1988, 110, 1229-1231. (b) Capacci, A. G.; Malinowski, J. T.; McAlpine, N. J.; Kuhne, J.; MacMillan, D. W. C. Direct, Enantioselective $\alpha$-Alkylation of Aldehydes Using Simple Olefins. Nat. Chem. 2017, 9, 1073-1077.
(26) Morse, D.; Nicewicz, D. A. Divergent Regioselectivity in Photoredox-Catalyzed Hydrofunctionalization Reactions of Unsaturatedamides and Thioamides. Chem. Sci. 2015, 6, 270-274. 
Deconstruction/Hydrogenation of Alcohols

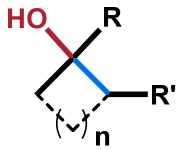

Alcohols: tertiary secondary primary

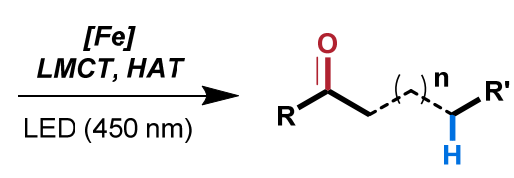

42 examples up to $96 \%$ yield 